\title{
Editorial
}

\section{Adolescent experiences in gaining academic and social competence}

The educational experiences of adolescents are featured in this special issue. How effectively an adolescent negotiates the challenges of schooling and thus opens the way to competence in meeting adult challenges is a focus of considerable research. The authors in this issue address various aspects of this topic. Some of this work is directed to the learning strategies, academic stress, and coping with school demands. Some of the work is directed to the social support available in schools and the benefits of social interventions in school settings to enhance cooperation and coping. Questions about how the adolescents themselves or the social supports available to them account for progress are a dynamic theme under discussion in this issue.

The conceptual nature of adolescence as a person in transition from child to adult has been redefined over the last 50 years. Once an unpleasant and unsympathetic creature precariously balanced on the brink of disastrous error, the adolescent is being viewed more positively and offered more constructive aid. The adolescent wracked by the internal conflicts of Sturm und Drang and of identity crisis (Erikson, 1959) remains a familiar if simplistic rendering of a process of self-discovery. Yet the role of stress in adolescent development is a continuing concern in work with adolescents and is canvassed in this issue (e.g., academic and social stress, anticipatory reactions that interfere with learning, everyday and chronic stress, and ambiguous stress). What used to be seen as an identity crisis is now reconceptualised as psychological stress: "A particular relationship between the person and environment that is appraised by the person as taxing or exceeding his or her resources and endangering his or her well-being" (Lazarus \& Folkman, 1984, p. 19). Following the historically late surge of empirical research on adolescence (Adelson, 1980), the expectation that all adolescents experienced difficulty during this developmental phase gave way to concepts of alternative developmental paths (Compas, Hinden, \& Gerhardt, 1995).

Despite oft-repeated pleas to "de-dramatize" adolescence..., frequent reminders that adolescence is not a period of "normative disturbance", and accumulating evidence that the majority of teenagers weather the challenges of the period without developing significant social, emotional, or behavioral difficulties..., the study of problem behavior continued to dominate the literature on adolescent development during the 1980 s and 1990s.

(Steinberg \& Morris, 2001, p. 85)

Some studies in this issue are concerned with adolescent problem behaviour and how to avoid such problems (Lerner \& Galambos, 1998), but 
most of the studies are also concerned with healthy adolescent development and the growth of competencies (Steinberg \& Morris, 2001). Three new directions in adolescent research identified by Steinberg and Morris (2001) are also represented in this issue. Participants include diverse populations of adolescents (homeless, educationally at risk, sexual offenders), adolescents and their siblings, and adolescents functioning in exam contexts (particularly the Victorian Certificate of Education). There is much scope for extending Australian research in these areas.

The age-bounded definition of adolescence in this special issue was somewhat stretched to accommodate preteen entry to and postteen exit from this important decade. Practitioners who work with adolescents from 9 to 25 years should find something of interest. In this special issue, Grant reviewed reflective academic strategies to enhance university learning of the emerging adult. Kouzma and Kennedy found some evidence that self-efficacy but not social support mediated secondary examination stress and argued for more research on how adolescents appraise academic stress. Warren found that adolescents had a range of coping strategies to deal with school pressures. Barrett, Rasmussen, and Healy established that inclusion of siblings in family interventions in Obsessive Compulsive Disorder reduced sibling anxiety and accommodation of the disorder. Meadowcroft and Charman found that level of completed education rather than time out of home predicted socialisation status of homeless adolescent young women and urged efforts to maintain homeless adolescents in school. Davidson and Versluys trained adolescents in conflict resolution skills and reported skill gains in untrained peers. Cotta, Frydenberg, and Poole trained adolescents in coping skills and reported decreases in nonproductive coping.

Adolescence and high schools go together for most young people. Research in high school settings is a complicating aspect of research on adolescents. Studying adolescents, whether for normative healthy or for socially challenging patterns of development, invokes ethical issues of appropriateness, confidentiality, and sample specificity. Obtaining access to students is a basic difficulty that is becoming tightly linked to ethical screening of research proposals in universities. There are related questions about how participating in large scale testing on many tests has value to adolescents in the general population sufficient to warrant diversion from their learning time in school. There are complementary issues of protecting from excessive clinical investigation those subgroups of adolescents with characteristics with research currency. Nisbet, in a brief report on a research centre for adolescent sex offenders, cautioned against drawing conclusions from this clinical subgroup and noted that low rates of reporting of offenses means unrepresentative sampling. The difficulties of school-based research on adolescents include the vagaries of access to the government system, the fragmenting effects of secondary school curricula on sample selection, and the time in consultation with many teachers. As adolescence research becomes more applied and more oriented to preventative intervention in school settings, such difficulties can be expected to multiply. Informed consent by principals, teachers, parents, and adolescents (and by ethics 
committees) requires strong cogent arguments and much patience. More participatory research that involves adolescents in the research process may be as time-consuming but more principled.

This issue was deferred to allow a complete issue on adolescence to be published. The 2001 issues, which are in preparation, concern children and the law and socioemotional aspects of child development. Manuscripts for 2002 issues may be submitted.

\section{References}

Adelson, J. (1980). Handbook of adolescent psychology. New York: Wiley.

Compas, B. E., Hinden, B. R., \& Gerhardt, C. A. (1995). Adolescent development: Pathways and processes of risk and resilience. Annual Review of Psychology, 46, 265-293

Erikson, E. H. (1959). Identity and the life cycle. Psychological Issues, 1, 18164.

Lazarus, R. S., \& Folkman, S. (1984). Stress, appraisal, and coping. New York: Springer.

Lerner, R. M., \& Galambos, N. L. (1998). Adolescent development: Challenges and opportunities for research, programs, and policies. Annual Review of Psychology, 49, 413-446.

Steinberg, L., \& Morris, A. S. (2001). Adolescent development. Annual Review of Psychology, 52, 83-110.

Fiona Bryer

Editor 